\title{
Targeting HMGA2 in Retinoblastoma Cells in vitro Using the Aptamer Strategy
}

\author{
Venkatesan Nalini ${ }^{a}$ b $\quad$ Perinkulam Ravi Deepa ${ }^{c}$ Rajeswari Raguraman ${ }^{a}$ \\ Vikas Khetan $^{d}$ Maddy Ashwin Reddye Subramanian Krishnakumar ${ }^{a}$ \\ a Department of Larsen \& Toubro Ocular Pathology, The Kamalnayan Bajaj Institute for Research in Vision \& \\ Ophthalmology, Vision Research Foundation, Chennai, birla Institute of Technology and Science (BITS), and \\ 'Department of Biological Sciences, Birla Institute of Technology and Science (BITS), Pilani, and d Department of \\ Vitreoretina and Oncology, Medical Research Foundation, Sankara Nethralaya, Chennai, India; ${ }^{\text {Department }}$ of \\ Ophthalmology, Barts Health NHS Trust, London, UK
}

\section{Key Words}

HMGA2 · HMGA2-aptamer · TGF $\beta$-SMAD4 - Retinoblastoma · Etoposide

\begin{abstract}
High-mobility group A2 (HMGA2) protein regulates retinoblastoma (RB) cancer cell proliferation. Here, a stable phosphorothioate-modified HMGA2 aptamer was used to block HMGA2 protein function in RB cells. HMGA2-aptamer internalisation in RB cells (Y79, Weri Rb1) and non-neoplastic human retinal cells (MIO-M1) were optimised. Aptamer induced dose-dependent cytotoxicity in RB cancer cells $(0.25-$ $1.5 \mu \mathrm{M})$. Increased expression of TGF $\beta$, SMAD4, CDH1, BAX, CASP 3, PARP mRNA and decreased SNAI1, BCl2 mRNA levels in aptamer-treated RB cells suggests the activation of TGF $\beta$ SMAD4-mediated apoptotic pathway. Synergistic effect with etoposide was observed in aptamer treated RB cells ( $p$ value $\leq 0.05$ ). No significant toxicity was observed in non-neoplastic retinal cells.

(c) 2016 S. Karger AG, Basel
\end{abstract}

\section{Introduction}

Retinoblastoma (RB) is a primary intraocular childhood tumour. The RB tumours reported in India are at an advanced stage with high histopathological risk factors during the time of clinical presentation $[1,2]$. Currently, focal therapy, systemic chemotherapy and in selected cases, intra-arterial and intra-vitreal chemotherapy for vitreous seeds and/or enucleation are part of RB tumour management. New therapeutic targets are being identified using novel genomic tools [3] and novel molecules such are small RNAs, antagomirs [4] and aptamers [5, 6].

One molecule which has generated interest among therapeutic targets in $\mathrm{RB}$ is high-mobility group $\mathrm{A}$ (HMGA) proteins. HMGA proteins are expressed in many solid cancers and have the potential for targeted therapy $[7,8]$. This is because HMGA proteins are overexpressed during the early development of embryonic tissues, which ceases in the developed adult cells. However, these proteins are re-expressed in cancer cells [9]. Being, architectural transcriptional factors [10], HMGA proteins structurally do not form any conventional protein structures, but preferentially interact with AT-rich sequences (minor groove of B form DNA) through 'AT-

\section{KARGER}

E-Mail karger@karger.com www.karger.com/oop
(2) 2016 S. Karger AG, Base

$2296-4681 / 16 / 0024-0262 \$ 39.50 / 0$
Dr. Subramanian Krishnakumar

Department of Larsen \& Toubro Ocular Pathology, The Kamalnayan Bajaj Institute for Research in Vision \& Ophthalmology, Vision Research Foundation Old No. 18, New No. 41, College Road, Chennai 600006 (India)

E-Mail drkrishnakumar_2000@yahoo.com 
hooks' [11]. HMGA proteins consist of two isoforms (HMGA1 and HMGA2) and are known to involve multifunctional cellular processes, including gene regulation, cell differentiation and apoptosis $[10,12]$.

HMGA2 are over-expressed in many cancers namely breast cancer and leukaemia $[13,14]$. In these cancers, the overexpression of HMGA2 is reported to enhance tumour progression involving the $\mathrm{PI} 3 \mathrm{~K} / \mathrm{Akt} / \mathrm{mTOR}$, HMGA2-TET1-HOX signalling pathways $[13,14]$ and tumour invasiveness by inducing transforming growth factor $-\beta$ receptor II (TGF $\beta$ RII) and SMAD transducers in the TGF $\beta$ signalling pathway $[15,16]$.

Numerous studies have shown the expression of HMGA2 protein in RB tumour progression $[17,18]$. In addition, HMGA2 are known as transcription factors in the myogenesis of embryonic stem cells [19] and as the self-renewal regulators of retinal progenitor cells [20]. Suppression of HMGA2 activity contributes to cancer cell arrest and has been indicated in various tumour models including RB [21].

HMGA2 activity could be suppressed either at biogenesis (transcription inhibition by siRNA) or in its function (translated protein) $[8,18]$. Earlier, a stable DNA aptamer was used to inhibit HMGA1 protein to increase the efficiency of chemotherapeutic drug in pancreatic cancer cells using in-vitro models [8]. Aptamers, being short DNA/ RNA oligonucleotides are selected using the SELEX (Systematic Evolution of Ligands by Exponential Enrichment) technology and can be chemically synthesised. Among these aptamers, Macugen, an RNA aptamer, was earlier used to treat age-related macular degeneration [5] and AS1411, an FDA-approved DNA aptamer, was used to inhibit nucleolin (protein) in breast cancer cells to destabilise Bcl2 (mRNA) [22]. These aptamers could be used for targeted delivery in cancer cells using chimeric combinations with siRNA [23], miRNA or DNAzyme [24]. Their stability and efficacy could be increased with modifications such as phosphorothioate and locked nucleic acid [25-27].

\section{Materials and Methods}

Cell Culture and Transfection of ssDNA (Aptamers)

Human RB cell lines (Y79 and Weri Rb1; Riken Cell Bank, Japan), non-neoplastic human Müller glial cell line (MIO-M1, a kind gift from G.A. Limb, UCL Institute of Ophthalmology, London) were used in the study. RB cancer cells and non-neoplastic cells were transiently transfected with ssDNA: AT-rich sequence [HMGA2aptamer (AT)] and scramble-aptamer (Scr) using Lipofectamine ${ }^{\mathrm{TM}}$ 2000. The aptamer sequences are referred from an earlier report [8] and are as follows: HMGA2-aptamer (AT-rich sequence): ${ }^{*} \mathrm{G}^{*} \mathrm{G}^{*} \mathrm{~A}$ ${ }^{*} A^{*} A^{*} A * A * A * T * T * T * T * T * T^{*} A * A * A * A * A * A{ }^{*}{ }^{*} C * C$; scramble- aptamer (mix sequence): $C^{*} C^{*} C^{*} A^{*} C^{*} T^{*} G^{*} C^{*} A^{*} G^{*} T^{*} C^{*} G^{*} G^{*} A^{*}$ $C^{*} T^{*} C^{*} A^{*} C^{*} T^{*} C^{*} G^{*} C$. The stability of the aptamer is enhanced by the phosphorothioate modification $\left(^{*}\right)$ as mentioned earlier [8]. These synthesised oligonucleotides were FITC/biotin-conjugated and HPLC (RP1) purified (Sigma Aldrich, USA).

\section{Cell Cytotoxicity and Viability Assays}

About 5,000 cells per well of a 96-well plate (coated with $0.01 \%$ poly-L-lysine) were used for these assays. Lactate dehydrogenase (LDH) activity in the 0.25-1.5 $\mu \mathrm{M}$ aptamer treatment was measured at the end of $24 \mathrm{~h}$ using LDH cytotoxicity assay kit (Cat. No. 04744926001, Roche, India) following the manufacturer's instructions. The percentage of cellular cytotoxicity was computed by measuring the total level of LDH released into the culture supernatant following the manufacturer's protocol. Cell viability was measured by using the MTT assay protocol in a treatment range of $0.25-1.5 \mu \mathrm{M}$ of aptamer concentrations for 24,48 and $72 \mathrm{~h}$ of incubation. The percentage of cell viability in aptamer-treated cells was computed relative to the untreated control cells.

Based on the outcomes of these assays, the cytotoxic concentration of the present aptamer was obtained and used for the remaining functional assays.

\section{Cell Proliferation Assay}

Cell proliferation assay was carried out using the CyQUANT NF cell proliferation assay kit (Cat. No. C35007, Invitrogen, India) following the manufacturer's instruction. The percentage of cell proliferation relative to untreated control cells was analysed after treating cells with aptamers at a concentration of $0.5 \mu \mathrm{M}$ for $24 \mathrm{~h}$.

\section{Internalisation Assay}

For microscopic observation, RB cells were seeded on a $0.1 \%$ poly-L-Lysine, transfected with FITC-conjugated ssDNA sequence and incubated for $48 \mathrm{~h}$. Following incubation, the cells were washed; DAPI $(1: 1,000)$ was stained for $15 \mathrm{~min}$ and viewed under fluorescent microscope (Carl Zeiss Axio Observer, Germany). The percentage of aptamers that entered into the cells at 24, 48, 72 and $96 \mathrm{~h}$ of incubation were measured using flow cytometer (BD FACS, Calibur, Becton-Dickinson, Franklin Lakes, N.J., USA).

\section{Cell Cycle Analysis}

The percentage of cell cycle stages upon $0.5 \mu \mathrm{M}$ aptamer treatment was analysed at the end of $48 \mathrm{~h}$ of incubation using propidium iodide stain. Transfected and untransfected cells were fixed with $70 \%$ cold ethanol for $30 \mathrm{~min}$, washed twice with ice cold $1 \times$ PBS and incubated at $37^{\circ} \mathrm{C}$ for $2 \mathrm{~h}$ in $1 \times$ PBS buffer containing 100 $\mu \mathrm{g} / \mathrm{ml} \mathrm{RNase} \mathrm{A}$ and $5 \mu \mathrm{g} / \mathrm{ml}$ propidium iodide. Cells were analysed using flow cytometry (FACS Calibur; Becton-Dickinson, Franklin Lakes, N.J., USA).

\section{RNA Isolation and $q R T-P C R$}

Total RNA from the aptamer-treated cells were isolated using TRI reagent (Invitrogen, India). About $1 \mu \mathrm{g}$ of total RNA were transcribed to complementary strand using oligo dT primers and reverse transcriptase as per manufacturer's protocol (Sensiscript II; Cat. No. 205211, Qiagen, Santa Clara, Calif., USA). Gene expression levels of TGF $\beta, S M A D 4$, SNAI1, CDH1, Bcl2, BAX, BIM, $P A R P$ and CASP3 were detected by using Universal $\mathrm{RT}^{2}$ Real Time $^{\mathrm{TM}}$ SyBr Green/ROX PCR master Mix (Qiagen, SABiosciences, USA) using specific primers (see online suppl. table 1; see www. 


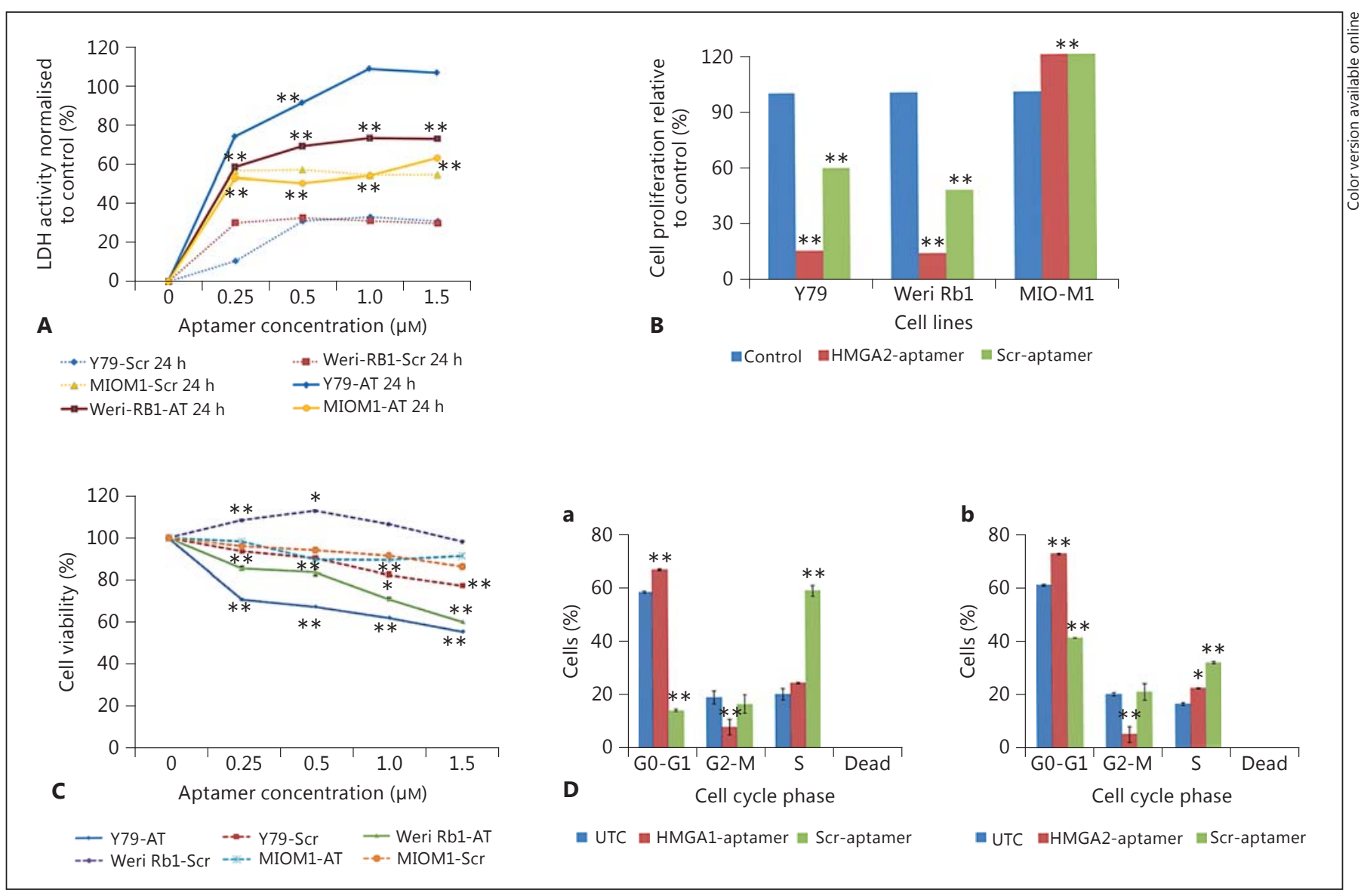

Fig. 1. Anti-cancer effects of HMGA2-aptamers in cultured RB and MIO-M1 cells. A LDH activity assay of cytotoxicity. Percentage of $\mathrm{LDH}$ activity measured at $0.25,0.5,1.0$ and $1.5 \mu \mathrm{M}$ at the end of $24 \mathrm{~h}$ of HMGA2-aptamer (AT)-treated RB cells and MIO-M1 cells. Continuous line indicates $\mathrm{LDH}$ activity in HMGA2-aptamer-treated RB and non-neoplastic MIO-M1 cells. Dotted line indicates LDH activity in scramble-aptamer (Scr)-treated RB cancer and non-neoplastic MIO-M1 cells. B CyQUANT assay of cell proliferation. Percentage of proliferation relative to untransfected cells (control) in $0.5 \mu \mathrm{M}$ aptamer treatment in RB cancer and MIOM1 cells at the end of $48 \mathrm{~h}$ of incubation. C Cell viability (MTT).

karger.com/doi/10.1159/000447300 for all online suppl. material). Data analysis was carried out based on ${ }^{\Delta \Delta} \mathrm{Ct}$ values of genes, derived by using commercial software (SDS v1.3; ABI) [28]. Relative expression values for all these genes were normalised to the GAPDH/18s as endogenous control. The unit of fold change was expressed in $\log _{2}$ ratios.

\section{Statistical Analysis}

The experiments were carried out in triplicate, and the values were expressed as mean \pm SD. One-way ANOVA, independentsample $t$ test, Mann-Whitney U and paired Student's t test were used to derive the significance of the test groups. A p value $\leq 0.05$ was considered as significant.
Percentage of cell viability measured at $0.25,0.5,1.0$ and $1.5 \mu \mathrm{M}$ at the end of $48 \mathrm{~h}$ of aptamer treatment in RB cancer and MIO-M1 cells. Continuous line indicates cell viability in HMGA2-aptamertreated RB cells. Dotted line indicates cell viability in HMGA2aptamer-treated MIO-M1 cells and scramble-treated RB and MIO-M1 cells. D Cell cycle analysis (propidium iodide stain) in 0.5 $\mu \mathrm{M}$ of aptamers at the end of $48 \mathrm{~h}$ of incubation. The bar graph of $\mathrm{RB}$ cells at various stages of cell cycle in HMGA2-aptamer and scramble-aptamer treatment: Y79 cells (a) and Weri Rb1 cells (b). In all these assays, error bars represent the SD of triplicate experiments $\left({ }^{*} \mathrm{p}<0.05,{ }^{* *} \mathrm{p}<0.01\right)$. UTC $=$ Untransfected cells.

\section{Results and Discussion}

In the current study, we have used a phosphorothioate-modified DNA aptamer to target the HMGA2 protein. Watanabe et al. [8] reported the application of this aptamer against HMGA1 to increase the chemotherapeutic efficacy in pancreatic cancer cells using an in vitro model. They selected this aptamer because it inhibited both the HMGA forms (HMGA1/HMGA2) and because of its structural stability (phosphorothioate-modified DNA) to resist the endonuclease activity (in vivo) [8]. 


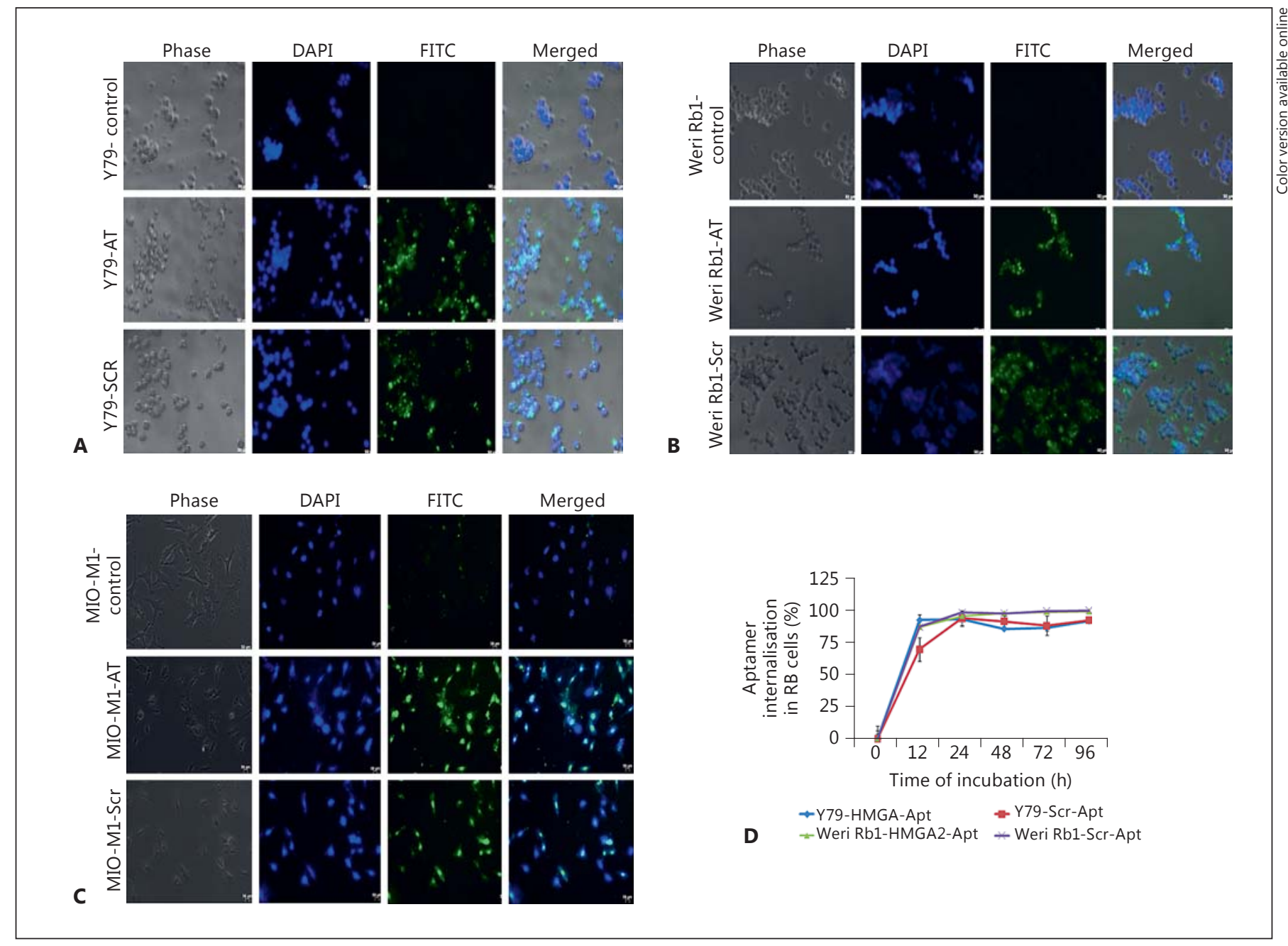

Fig. 2. Photomicrographs of HMGA2-aptamer-treated RB cells and non-neoplastic MIO-M1 cells in $0.5 \mu \mathrm{M}$ of aptamers at the end of $48 \mathrm{~h}$ of incubation. A Y79 cells. B Weri Rb1 cells. C MIO-M1 cells. Photomicrographs of phase contrast, DAPI stain, FITC stain and merged images are indicated serially in rows. Microscopic ob- servations in untranfected control, HMGA2-aptamer (AT)- and scramble-aptamer (Scr)-transfected cells are indicated in the columns. D Quantitative estimation of aptamers internalised within $\mathrm{RB}$ cells are represented graphically. Error bars represent SD of the triplicate experiments.
Anti-Cancer Effect of HMGA2-Aptamer in RB Cells

Using three different assays (LDH cytotoxicity, MTT and CyQUANT), the anti-cancer effect of HMGA2-aptamer was probed in two RB cell lines (Y79 and Weri $\mathrm{Rb} 1$ ). The spectrophotometric analyses of LDH activity in two RB cell lines and one non-neoplastic retinal cell line revealed the differential cytotoxicity after $24 \mathrm{~h}$ of treatment with HMGA2-aptamer and scramble-aptamer relative to untreated control cells. HMGA2-aptamer treatment $(0.25-1.5 \mu \mathrm{M})$ induced cytotoxicity in both Y79 and Weri Rb1 cells in a concentration-dependent manner.
LDH activity in Y79 cells was $90.84 \%$ (vs. $30.53 \%$ with scramble-aptamer treatment), and in Weri Rb1 cells it was $68.51 \%$ (vs. $32.20 \%$ with scramble-aptamer treatment) after HMGA2-aptamer treatment. These results indicated the $0.5 \mu \mathrm{M}$ concentration of HMGA2-aptamer to be sufficiently cytotoxic to RB cancer cells (fig. 1A).

The effects of the aptamer on cell proliferation and cell viability were determined after $48 \mathrm{~h}$ of treatment. With the $0.5 \mu \mathrm{M}$ HMGA2-aptamer treatment, a decrease in RB cell proliferation [Y79 (15.3\%), Weri Rb1 (13.49\%)] was observed in comparison with untransfected RB cells (fig. 1B). In 0.5 $\mu \mathrm{M}$ HMGA2-aptamer-transfected RB

Ocul Oncol Pathol 2016;2:262-269 


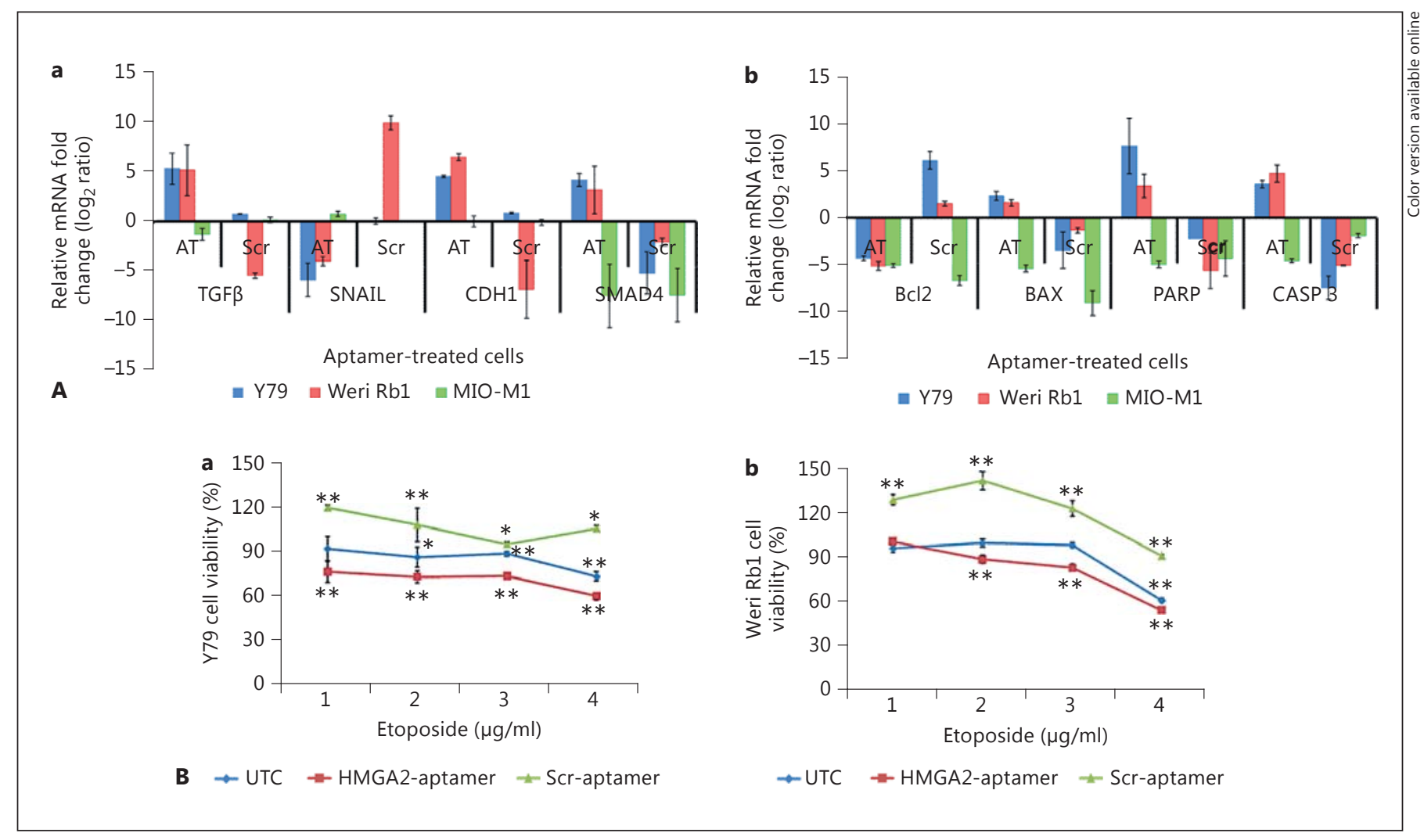

Fig. 3. A mRNA expression of selected genes. a Panel 1 (TGFB SMAD4 pathway) - TGF $\beta$, SNAI1, CDH1 and SMAD4. b Panel 2 (apoptotic pathway) - Bcl2, BAX, PARP and CASP3. Relative mRNA expressions were determined by qRT-PCR in aptamertransfected RB cancer and non-neoplastic MIO-M1 cells, and compared with the respective untransfected cells. Error bars rep- resent the SD of triplicates. B Synergistic modulation of etoposide dosage by HMGA2-aptamer treatment in RB cells. After $48 \mathrm{~h}$ of $0.5 \mu \mathrm{M}$ aptamer treatment with varying concentrations of etoposide $(1.0-4.0 \mu \mathrm{g})$, cell viability was measured: Y79 cells (a) and Weri Rb1 cells (b). Error bars represent the SD of triplicate values $\left({ }^{*} \mathrm{p} \leq 0.05,{ }^{* *} \mathrm{p} \leq 0.01\right)$. UTC $=$ Untransfected cells. cells, the MTT assay revealed a decrease in cell viability of $67.03 \%$ in Y79 cells and $83.2 \%$ in Weri Rb1 cells relative to the untransfected control at the end of $48 \mathrm{~h}$ of treatment (fig. 1C).

The complementary assays to investigate the cytotoxicity in HMGA2-aptamer treatment revealed minimal or negligible cytotoxicity in normal MIO-M1 cells (LDH activity: 49.95\%; fig. 1A). Both MTT and CyQUANT assays showed a high viability of the MIO-M1 cells (fig. 1B, C). Cytotoxicity was not evident in the scramble-treated cells which showed a cell viability of $>90 \%$ in RB and MIO-M1 cells (fig. 1C). These values were much higher than the specific HMGA2-aptamer treatment.

Taken together, these results indicated that $0.5 \mu \mathrm{M}$ HMGA2-aptamer decreases RB cells viability and proliferation. Therefore, this concentration was selected for further analyses.

\section{Internalisation Assay of DNA Aptamers}

After transfection with $0.5 \mu \mathrm{M}$ of aptamers, RB cells and MIO-M1 cells were observed microscopically to evaluate the penetration of the aptamers in the nuclei of the cells (fig. 2A-C). Aptamer uptake in RB cancer cells was recorded at the end of $12,24,48,72$ and $96 \mathrm{~h}$ (fig. 2D). Nearly $90 \%$ of aptamers were internalised at the end of $96 \mathrm{~h}$.

\section{Regulation of Cell Cycle by Aptamers}

With the $0.5 \mu \mathrm{M}$ HMGA2-aptamer treatment in RB cells, we observed marked changes in various cell cycle stages. The anti-proliferative effect in the HMGA2-aptamer-treated RB cells was observed in the $G_{2} / M$ phase (decrease) and the $\mathrm{S}$ phase (increase). While there was $18.8 \%$ in the $\mathrm{G}_{2} / \mathrm{M}$ and $19.8 \%$ in the $\mathrm{S}$ phase of untransfected $Y 79$ cells, the reciprocal effect was seen in aptamer- 
treated $\mathrm{Y} 79$ cells, with $7.7 \%$ in the $\mathrm{G}_{2} / \mathrm{M}$ and $23.9 \%$ in the $\mathrm{S}$ phase. A similar effect was observed in aptamer-treated Weri Rb1 cells (fig. 1D). Scramble-aptamer-treated RB cells showed a decrease in $G_{0} / G_{1}$ and an increase in the $S$ phase relative to the untreated RB cells (fig. 1D). This may be attributed to a low level of toxicity at moderate doses of scramble-aptamer that has been reported earlier in pancreatic cancer cells [8].

The results presented above clearly indicate that HMGA2-specific aptamers exert a cytotoxic and antiproliferative effect on RB cancer cells with negligible toxicity in normal cells.

Molecular Dysregulation in Aptamer-Treated RB Cells In order to understand the molecular changes in the HMGA2-aptamer-treated cells, we analysed a panel of eight gene transcripts (TGF $\beta, S N A I 1, C D H 1, S M A D 4$, $B c l 2, B A X, P A R P$ and $C A S P 3$ ) based on their regulatory coexistence [16] and apoptotic induction. Online supplementary table 2 reflects these gene expression values. No significant gene expression changes were observed between untransfected and transfected MIO-M1 cells (fig. 3A).

HMGA2 protein contributes to tumour progression through the $T G F \beta$-mediated pathway by transcriptional regulators of E-cadherin (CDH1) such as the zinc finger protein SNAI1 [16]. Earlier, we observed that HMGA2 gene silencing in $\mathrm{RB}$ cells resulted in the suppression of SNAI1 and activation of $C D H 1$, leading to the reduction of RB cell proliferation [21]. The role of SMAD4 gene in tumour suppression [29], induction of apoptosis [30] and chemoresistance [31] has been well documented.

In the current study, HMGA2-aptamer-treated RB cells showed a reduced SNAI1 mRNA with a corresponding increase in $\mathrm{CDH} 1 \mathrm{mRNA}$ (fig. 3A; online suppl. table 2). There was no change in the SNAI1 and E-cadherin (CDH1) mRNA levels or in the TGF $\beta$-SMAD4 pathway in scramble-aptamer-treated RB cells, confirming the specificity of the HMGA2 aptamer (fig. 3A; online suppl. table 3). The inverse expression of SNAI1 and CDH1 in RB primary tumours [21] suggests their contribution to tumour progression. Our present findings corroborate this regulation, where the HMGA2-aptamer modulates these expressions, favouring cancer cell control.

SMAD4 upregulation was observed in both HMGA2aptamer-treated RB cells, where Y79 cells showed a slightly higher induction compared to Weri Rb1 (Y79: 4.17 and Weri Rb1: $3.15 \log _{2}$ ratio) (fig. 4; online suppl. table 3). Taken together, the activation of SMAD4 along with $T G F \beta$ in the current study indicates their contribution towards the RB cell cycle arrest and anti-proliferation activity. Molecular de-regulation induced by HMGA2-aptamer resulting in $\mathrm{RB}$ cancer cell death is schematically illustrated in figure 4.

Further, the HMGA2-aptamer was evaluated for any effect on modulating the dosage of the standard chemotherapeutic drug etoposide. Based on the results, the 0.5 $\mu \mathrm{M}$ concentration of HMGA2-aptamer was used for studying the synergistic effect of etoposide. We observed a significant decrease in cell viability ( $\mathrm{p}$ value for $\mathrm{Y} 79=$ 0.02 and Weri $\mathrm{Rb} 1=0.05$ ) in the presence of etoposide together with HMGA2 aptamer in RB cells compared to that of etoposide-treated RB cells. Only $2-3 \mu \mathrm{g} / \mathrm{ml}$ of etoposide was needed to achieve $\mathrm{IC}_{70}$ in both $\mathrm{RB}$ cancer cells treated with aptamer (fig. 3B). Interestingly, however, a high dosage of $4.35 \mu \mathrm{g} / \mathrm{ml}$ in untransfected Y79 and 4.12 $\mu \mathrm{g} / \mathrm{ml}$ in untransfected Weri $\mathrm{Rb} 1$ was required to induce the same $\mathrm{IC}_{70}$ toxicity (fig. $3 \mathrm{~B}$ ). These results suggest that HMGA2-aptamer treatment in RB cells synergistically modulates the dosage of the chemotherapeutic drug (etoposide) without compromising its anti-cancer efficacy. In a previous study, the HMGA-DNA aptamer had increased gemcitabine sensitivity in human pancreatic cancer cell lines [8]. However, the molecular mechanism contributing to chemosensitisation of pancreatic cancer cells was not known. In addition, the concurrent activation of $B A X$, together with the suppression of $B c l 2$, substantiates the onset of SMAD4-activated apoptotic pathway in HMGA2-aptamer-treated RB cells (fig. 3A; online suppl. table 2). Activation of the effector apoptotic molecule CASP 3 promotes the cleavage of downstream nuclear and cytoplasmic substrates including PARP [32, 33]. Thus, activation of CASP 3 and PARP observed in HMGA2-aptamer-treated RB cells indicates the induction of the apoptotic pathway (fig. 3A).

\section{Conclusions}

The stable HMGA2-aptamer induced cytotoxicity and reduced the RB cell proliferation considerably. The TGF $\beta$ SMAD4 pathway could be influenced by HMGA2-aptamer in RB cells. There was a synergistic effect of HMGA2-aptamer with a chemotherapy drug, etoposide. The absence of aptamer-induced specific changes in normal Müller glial cells suggests the promising potential of HMGA2-aptamer for RB treatment. However, there are still challenges remaining in the use of this aptamer. Further studies are needed to understand its intraocular efficacy using an orthotopic model of RB. 


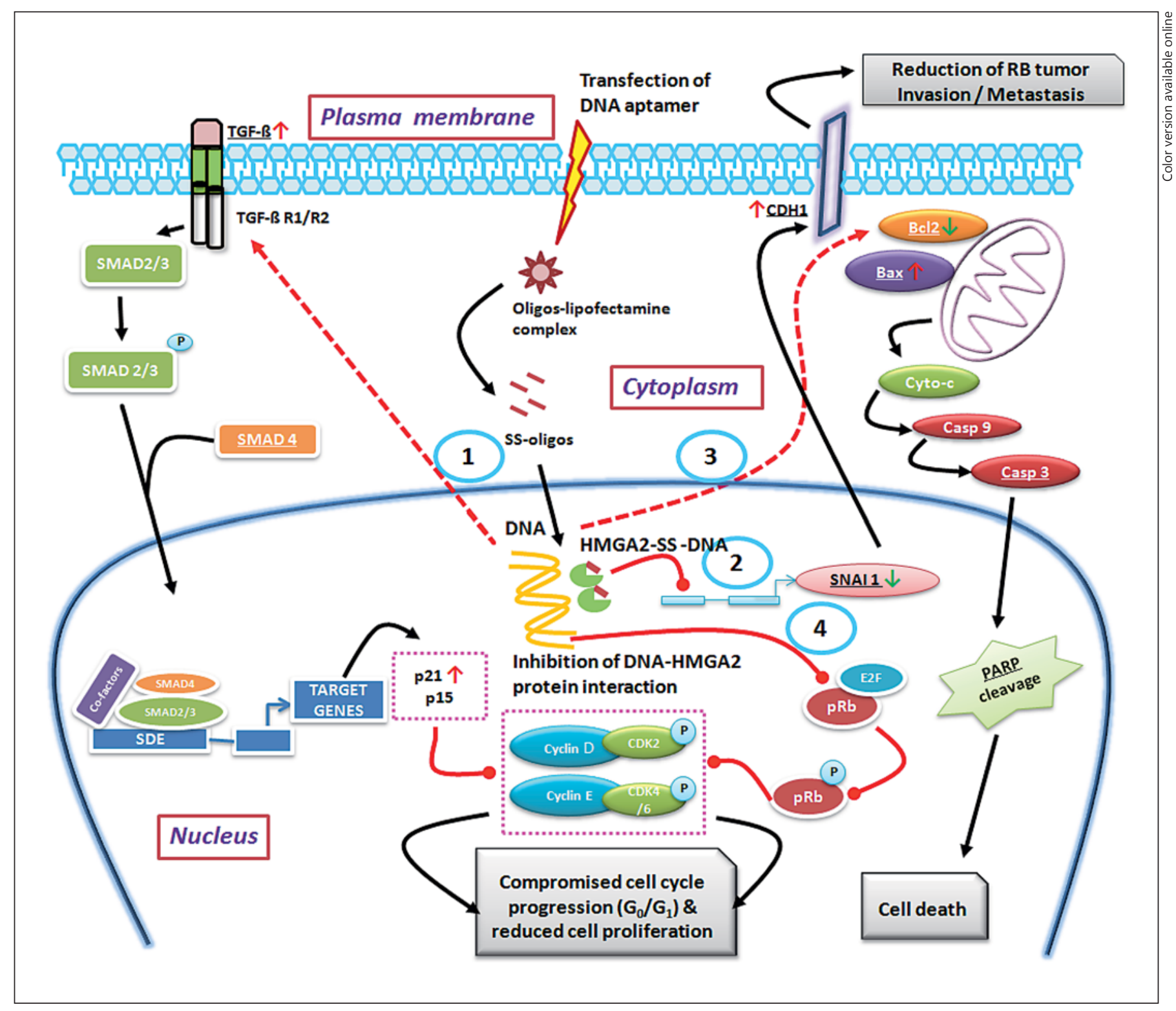

Fig. 4. Molecular de-regulations and function validation in HMGA2-aptamer-treated RB cancer cells. Schematic representation of the key de-regulated genes in the post-inhibition of HMGA2 protein function in RB cells contributing to the compromised cell cycle phase, reduced cell proliferation and increased apoptosis of cancerous cells. Following may be the possible molecular mechanisms induced by HMGA2-aptamers (ssDNA) in RB cells resulting in cancer control. (1) Inhibition of the HMGA2 protein and DNA interaction resulting in the activation of SMAD4-dependent TGF $\beta$-mediated apoptosis. Upregulation of p21 and downregulation of CDK4 in the absence of HMGA2 protein within RB cells has been reported earlier $[21,34]$. These molecular changes may contribute to the compromised cell cycle changes and reduced cell proliferation. (2) Obstruction of HMGA2 protein function reduced the expression levels of SNAI1 resulting in the activation of $\mathrm{CDH} 1$ (E-cadherin). Increased levels of $\mathrm{CDH} 1$ transcripts could contribute to the reduction in the RB tumor invasion and metastasis. (3) Suppression of $\mathrm{Bcl} 2$ and the activation of Bax resulted in the release of caspase 3 and PARP cleavage which in turn contributed to the RB cell death. Red arrow-headed dotted lines indicate the activation of molecules, while the red blunt head indicates the suppression of molecules. Black arrow-headed line indicates the activation of the downstream molecules. Underlined genes are validated in the current study. Colours refer to the online version only. 


\section{Acknowledgement}

This work was supported by a research grant from Childhood Eye Cancer Trust (CHECT Foundation), London, UK, and Department of Biotechnology (DBT), Government of India (No. BT/01/CE1B/11/V/16, Programme Support for research on Retinoblastoma).

\section{Statement of Ethics}

This study has been reviewed and approved by the institutional ethics committee (Vision Research Foundation, Sankara Nethralaya, India; 249B-2011-P).

\section{Disclosure Statement}

No competing financial interests exist.

\section{References}

1 Sengupta S, Krishnakumar S, Sharma T, et al: Histopathology of retinoblastoma: does standardization make a difference in reporting? Pediatr Blood Cancer 2013;60:336-337.

2 Dimaras H, Kimani K, Dimba EA, et al: Retinoblastoma. Lancet 2012;379:1436-1446.

3 Theriault BL, Dimaras H, Gallie BL, et al: The genomic landscape of retinoblastoma: a review. Clin Experiment Ophthalmol 2014;42: 33-52.

4 Kandalam MM, Beta M, Maheswari UK, et al: Oncogenic microRNA 17-92 cluster is regulated by epithelial cell adhesion molecule and could be a potential therapeutic target in retinoblastoma. Mol Vis 2012;18:2279-2287.

5 Kanwar JR, Roy K, Maremanda NG, et al: Nucleic acid-based aptamers: applications, development and clinical trials. Curr Med Chem 2015;22:2539-2557.

6 Pritchard EM, Dyer MA, Guy RK: Progress in small molecule therapeutics for the treatment of retinoblastoma. Mini Rev Med Chem 2016; 16:430-454.

7 Pentimalli F, Dentice M, Fedele M, et al: Suppression of HMGA2 protein synthesis could be a tool for the therapy of well differentiated liposarcomas overexpressing HMGA2. Cancer Res 2003;63:7423-7427.

8 Watanabe $M$, Sheriff $S$, Lewis $\mathrm{KB}$, et al: HMGA-targeted phosphorothioate DNA aptamers increase sensitivity to gemcitabine chemotherapy in human pancreatic cancer cell lines. Cancer Lett 2012;315:18-27.

9 Hirning-Folz U, Wilda M, Rippe V, et al: The expression pattern of the Hmgic gene during development. Genes Chromosomes Cancer 1998:23:350-357.

10 Reeves R: Molecular biology of HMGA proteins: hubs of nuclear function. Gene 2001; 277:63-81.

11 Reeves R, Nissen MS: The A.T-DNA-binding domain of mammalian high mobility group I chromosomal proteins. A novel peptide motif for recognizing DNA structure. J Biol Chem 1990;265:8573-8582.

12 Sgarra R, Rustighi A, Tessari MA, et al: Nuclear phosphoproteins HMGA and their relationship with chromatin structure and cancer. FEBS Lett 2004;574:1-8.
13 Sun $\mathrm{M}$, Song CX, Huang $\mathrm{H}$, et al: HMGA2/ TET1/HOXA9 signaling pathway regulates breast cancer growth and metastasis. Proc Natl Acad Sci USA 2013;110:9920-9925.

14 Tan L, Wei X, Zheng L, et al: Amplified HMGA2 promotes cell growth by regulating Akt pathway in AML. J Cancer Res Clin Oncol 2016;142:389-399.

15 Morishita A, Zaidi MR, Mitoro A, et al: HMGA2 is a driver of tumor metastasis. Cancer Res 2013;73:4289-4299.

16 Thuault S, Tan EJ, Peinado H, et al: HMGA2 and Smads co-regulate SNAIL1 expression during induction of epithelial-to-mesenchymal transition. J Biol Chem 2008;283:3343733446.

17 Venkatesan N, Kandalam M, Pasricha G, et al: Expression of high mobility group A2 protein in retinoblastoma and its association with clinicopathologic features. J Pediatr Hematol Oncol 2009;31:209-214.

18 Chau KY, Manfioletti G, Cheung-Chau KW, et al: Derepression of HMGA2 gene expression in retinoblastoma is associated with cell proliferation. Mol Med 2003;9:154-165.

19 Caron L, Bost F, Prot M, et al: A new role for the oncogenic high-mobility group A2 transcription factor in myogenesis of embryonic stem cells. Oncogene 2005;24:6281-6291.

20 Parameswaran S, Xia X, Hegde G, et al: Hmga2 regulates self-renewal of retinal progenitors. Development 2014;141:4087-4097.

21 Venkatesan N, Krishnakumar S, Deepa PR, et al: Molecular deregulation induced by silencing of the high mobility group protein A2 gene in retinoblastoma cells. Mol Vis 2012;18: 2420-2437.

22 Soundararajan S, Chen W, Spicer EK, et al: The nucleolin targeting aptamer AS1411 destabilizes Bcl-2 messenger RNA in human breast cancer cells. Cancer Res 2008;68:23582365 .

23 Subramanian N, Kanwar JR, Kanwar RK, et al: EpCAM Aptamer-siRNA chimera targets and regress epithelial cancer. PLoS One 2015; 10:e0132407.

24 Subramanian N, Kanwar JR, Akilandeswari B, et al: Chimeric nucleolin aptamer with survivin DNAzyme for cancer cell targeted delivery. Chem Commun (Camb) 2015;51:69406943.
25 Maremanda NG, Roy K, Kanwar RK, et al: Quick chip assay using locked nucleic acid modified epithelial cell adhesion molecule and nucleolin aptamers for the capture of circulating tumor cells. Biomicrofluidics 2015;9: 054110 .

26 Subramanian N, Kanwar JR, Kanwar RK, et al: Targeting cancer cells using LNA-modified aptamer-siRNA chimeras. Nucleic Acid Ther 2015;25:317-322.

27 Esposito V, Scuotto M, Capuozzo A, et al: A straightforward modification in the thrombin binding aptamer improving the stability, affinity to thrombin and nuclease resistance. Org Biomol Chem 2014;12:8840-8843.

28 Livak KJ, Schmittgen TD: Analysis of relative gene expression data using real-time quantitative PCR and the 2(-Delta Delta C(T)) Method. Methods 2001;25:402-408.

29 Hahn SA, Schutte M, Hoque AT, et al: DPC4, a candidate tumor suppressor gene at human chromosome 18q21.1. Science 1996;271:350353.

30 Yamazaki K, Masugi Y, Sakamoto M: Molecular pathogenesis of hepatocellular carcinoma: altering transforming growth factor-beta signaling in hepatocarcinogenesis. Dig Dis 2011;29:284-288.

31 Zhang B, Chen X, Bae S, et al: Loss of Smad4 in colorectal cancer induces resistance to 5-fluorouracil through activating Akt pathway. Br J Cancer 2014;110:946-957.

32 Huppertz B, Frank HG, Reister F, et al: Apoptosis cascade progresses during turnover of human trophoblast: analysis of villous cytotrophoblast and syncytial fragments in vitro. Lab Invest 1999;79:1687-1702.

33 Debatin KM: Cytotoxic drugs, programmed cell death, and the immune system: defining new roles in an old play. J Natl Cancer Inst 1997;89:750-751.

34 Venkatesan N, Deepa P, Vasudevan M, et al: Integrated analysis of dysregulated miRNAgene expression in HMGA2-silenced retinoblastoma cells. Bioinform Biol Insights 2014; 8:177-191. 